\title{
Strategic Maneuvering: A Synthetic Recapitulation
}

\author{
FRANS H. VAN EEMEREN and PETER HOUTLOSSER
}

Department of Speech Communication, Argumentation Theory and Rhetoric, Universiteit van Amsterdam, Spuistraat 134, Amsterdam 1012 VB, The Netherlands

E-mails: F.H.vanEemeren@uva.nl; P.Houtlosser@uva.nl

\begin{abstract}
As an introduction to the special issue on Perspectives on Strategic Maneuvering, this article provides a synthetic recapitulation of the various steps that were taken in developing the pragma-dialectical theory of strategic maneuvering. First, the concept of strategic maneuvering is described as a means to reconcile the simultaneous pursuit of dialectical and rhetorical aims. Second, strategic maneuvering is related to the various kinds of argumentative activity types in which it takes place. Third, the concept of dialectical profiles is discussed and the parameters that are pertinent to distinguishing between different types of strategic maneuvering. Fourth, the fallacies are viewed as derailment of strategic maneuvering. Fifth, as a case in point, strategic maneuvering with inconsistency is examined.
\end{abstract}

KEY WORDS: argumentation, argumentative activity type, dialectic, dialectical profile, fallacy, inconsistency, pragma-dialectics, rhetoric, strategic maneuvering, type of strategic maneuvering

\section{A PRAGMA-DIALECTICAL APPROACH TO THE ANALYSIS AND EVALUATION OF ARGUMENTATIVE DISCOURSE}

The pragma-dialectical theory of argumentation developed by van Eemeren and Grootendorst $(1984,1992,2004)$ enables the analyst of argumentative discourse to make a normative reconstruction of the discourse that results in an analytic overview of all elements that are pertinent to a critical evaluation (van Eemeren and Grootendorst, 1992). The analytic overview clarifies the difference of opinion at issue and the positions of the participants. It identifies the procedural and substantive premises that serve as the starting point of the discussion. It surveys the arguments and criticisms that are - explicitly or implicitly - advanced, the argument schemes that are used, the argumentation structures that are developed. And it determines the conclusion that is reached. The analysis is in every respect based on the pragmadialectical model of a critical discussion that provides a survey of all speech acts and combinations of speech acts that have a constructive function in the various stages of the process of resolving a difference 
of opinion on the merits and therefore provides an appropriate heuristic and analytic tool for reconstructing the resolution process. This reconstruction amounts to making explicit speech acts that remain implicit in the actual discourse but are relevant to the resolution process ('addition'), reformulating speech acts whose function would otherwise be opaque in an unequivocal way ('substitution'), rearranging speech acts whose order does not reflect their function in the resolution process in a more insightful way ('permutation'), and abandoning speech acts from consideration that do not play a part in the resolution process ('deletion') (van Eemeren, Grootendorst, Jackson, and Jacobs, 1993).

In certain cases, however, neither the textual presentation, nor contextual information in the strict sense or in the broad sense, nor general or specific background knowledge seem to offer enough evidence for a full reconstruction of the discourse, so that pragma-dialecticians - in a charitable fashion - take refuge to so-called maximal strategies aimed at making the analytic choices that do most justice to the purposes of a critical discussion, but remain, in fact, arbitrary ('maximal dialectical analysis,' 'maximal argumentative interpretation'). This predicament makes the analysis that can be achieved less comprehensive than desirable, its justification less firmly grounded than desirable, and an evaluation based on this analysis less thorough than desirable. In our view, the reconstruction that takes place in a pragma-dialectical analysis of argumentative discourse can be further refined and better accounted for if the standard version of the pragma-dialectical theory is extended by including a rhetorical dimension that makes it possible to take the strategic design of the discourse into consideration in the analysis (cf. Leff, 2006). A pragma-dialectical theory that is thus extended will, because the strategic function of argumentative moves is taken into account, also allow for a more realistic treatment of the fallacies in the evaluation of argumentative discourse (cf. Zarefsky, 2006). We therefore aimed for developing such an extended version of the pragma-dialectical theory of argumentation.

\section{STRATEGIC MANEUVERING TO COMBINE PURSUING DIALECTICAL AND RHETORICAL AIMS}

For most scholars of argumentation there is a yawning conceptual and communicative gap between a dialectical approach and a rhetorical approach to the study of argumentation (cf. Leeman, 1992; Toulmin, 2001). This gap hinders the development of a full-fledged theory of argumentation and is, in our view, unnecessary (cf. Wenzel, 1990). We want to bridge the gap by showing that rhetorical and dialectical approaches are, in fact, complementary (cf. Krabbe, 2002; Leff, 2002). In pragma-dialectics dialectic is defined pragmatically as a method for 
dealing systematically with critical exchanges in verbal communication and interaction 'that amounts to the pragmatic application of logic, a collaborative method of putting logic into use so as to move from conjecture and opinion to more secure belief' (van Eemeren et al., 1996: 214). As far as it is pertinent to pragma-dialectics, rhetoric is the theoretical study of the potential effectiveness of argumentative discourse in convincing or persuading an audience in actual argumentative practice. ${ }^{1}$ Starting from these definitions, there is no reason to assume that the rhetorical norm of artful persuasion is necessarily in contradiction with the dialectical ideal of reasonableness. In practice, argumentative moves that are considered rhetorically strong by a critical audience will almost certainly be in accordance with the dialectical norms applying to the discussion stage concerned. Viewed from this perspective, there is a sound basis for overcoming the traditional division between dialectic and rhetoric.

In our view, the gap between dialectic and rhetoric can be bridged by introducing the theoretical concept of 'strategic maneuvering' (van Eemeren and Houtlosser, 2002). Strategic maneuvering refers to the efforts arguers make in argumentative discourse to reconcile aiming for rhetorical effectiveness with maintaining dialectical standards of reasonableness. Each of the four stages in the process of resolving a difference of opinion by means of a critical discussion is characterized by having a specific dialectical objective. Because, as a matter of course, the parties want to realize these objectives to the best advantage of the position they have adopted, every dialectical objective has its rhetorical analogue. In each discussion stage, the rhetorical goals of the participants will be dependent on - and therefore run parallel with - their dialectical goals. As a consequence, the specification of the rhetorical aims the participants in the discourse are presumed to have must take place according to dialectical stage. This is the methodological reason why the study of strategic maneuvering that we propose boils down to a systematic integration of rhetorical insight in a dialectical - in our case, pragma-dialectical - framework of analysis. ${ }^{2}$

Strategic maneuvering manifests itself in argumentative discourse in the choices that are made from the 'topical potential' available at a certain stage in the discourse, in 'audience-directed framing' of the argumentative moves, and in the purposive use of 'presentational devices.' Although these three aspects of strategic maneuvering, which run parallel with classical areas of interest - topics, audience orientation and stylistics -, can be distinguished analytically, in actual argumentative practice they will usually work together (cf. Kauffeld, 2002; Tindale, 2004). We only say that a party exhibits a fully-fledged 'argumentative strategy' if this party's strategic maneuvering in the discourse consistently converges with respect to choosing from topical 
potential, adapting to audience demand, and utilizing presentational devices. Argumentative strategies in our sense are methodical designs of moves for influencing the result of a particular dialectical stage, and the discussion as a whole, to a certain party's advantage that manifest themselves at a certain stage of the discourse in a systematic, coordinated and simultaneous exploitation of the available opportunities. There are specific confrontation strategies, specific opening strategies, specific argumentation strategies and specific concluding strategies.

\section{STRATEGIC MANEUVERING IN DIFFERENT KINDS OF ARGUMENTATIVE ACTIVITY TYPES}

In practice, argumentative discourse takes place in different kinds of 'activity types,' which are to a greater or lesser degree institutionalized, so that certain practices have become conventionalized. Unlike theoretical constructs such as a critical discussion and other ideal models based on analytic considerations regarding the most pertinent presentation of the constitutive parts of a problem-valid procedure for carrying out a particular kind of discursive task, activity types and the speech events that are associated with them can be identified on the basis of careful empirical observation of argumentative practice. In the various activity types that can be distinguished in argumentative practice the conventional preconditions for argumentative discourse differ to some extent and these differences have an effect on the strategic maneuvering that is allowed. For some prominent activity types, such as 'adjudication,' 'mediation,' and 'negotiation,' we will describe the preconditions pertinent to the conduct of strategic maneuvering, and draw a comparison between them, in order to show how strategic maneuvering is affected by the opportunities and constraints of the activity type in which it takes place.

Adjudication aims for the termination of a dispute by a third party rather than the resolution of a difference of opinion by the parties themselves. It is commonly understood as taking a dispute to a public court, where a judge, after having heard both sides, will make a reasoned decision in favor of either one of the parties. The judge determines who is wrong and who is right according to a set of rules. Most of these rules are tantamount to specifications of rules for critical discussion aimed at promoting that the dispute be terminated in a reasonable way. There are, for instance, special rules concerning the division of the burden of proof, the data that can be considered as a common starting point and the kinds of proof that count as acceptable. In adjudication, the parties readjust their roles from trying to persuade each other to trying to convince the adjudicator. 
Mediation, a second activity type, starts from a difference of opinion that has led to a disagreement that the parties concerned cannot resolve by themselves, so that they have to take refuge to a third party that acts as a neutral facilitator of the discussion process and guides the parties in their cooperative (and sometimes less than cooperative) search for a solution. Unlike an adjudicator, the mediator does not have the power to terminate the disagreement. Irrespective of whether the disagreement concerns custody of the children of a divorced couple or the price that has to be paid for the reparation of a car, the mediator aims at helping the parties come to an arrangement that is satisfactory to both parties.

Negotiation is an activity type that starts from a conflict of interests rather than merely a difference of opinion. Unlike in adjudication and mediation, in negotiations the disputants are focussed on each other rather than on a presumably neutral third party. Negotiations prototypically aim for a compromise. Usually, the compromise will consist of the maximum amount of agreement that can be reached on the basis of the concessions that both parties are willing to make. A series of interest-related interactive speech events have developed that are aimed at reaching an outcome in which the interests of both sides in the negotiation are met to an extent that is mutually acceptable.

Starting from a comparative inventory of conventional preconditions for argumentative discourse in such activity types, we can show for each activity type how these preconditions discipline the conduct of strategic maneuvering. Using this approach, we can also provide a more detailed analysis of the way in which strategic maneuvering is disciplined by conventional preconditions in specific and sometimes more complex activity types such as 'public debate.' Public debate is a multi-varied activity type that is particularly relevant from the perspective of argumentation theory, especially from the perspective of our extended pragma-dialectical argumentation theory, because its institutionalization, as far as it goes, is aimed precisely at conventionalizing the conduct of argumentative discourse in a way that optimally serves both dialectical and rhetorical purposes.

\section{DIALECTICAL PROFILES AND TYPES OF STRATEGIC MANEUVERING}

In analyzing the type of strategic maneuvering that is carried out, for each category of strategic maneuvering the following parameters must be considered:

(1) the results that can be achieved;

(2) the routes that can be taken to achieve these results; 
(3) the constraints of the institutional context;

(4) the mutual commitments defining the argumentative situation.

In analyzing the strategic function of a particular case of maneuvering we have to take into account, first, which results can be achieved by making the argumentative move that is made, so that it can be explained what kind of outcome may be aimed for by this kind of strategic maneuvering. The spectrum of relevant options open to be filled out in the analytic overview can be of help in this endeavor. Second, we have to take into account which reasonable options are available when making the argumentative move so that it can be explained what route is taken by carrying out this particular kind of strategic maneuvering. The dialectical profile for the moves that are analytically relevant at this juncture in the discussion procedure can be of help in this endeavor (cf. Walton and Krabbe, 1995). Third, we have to take into account the institutional constraints of the argumentative discourse that is carried out, so that it can be explained what the conventional preconditions are that the strategic maneuvering must meet in this type of discourse. An understanding of the kind of activity type in which, or social background against which, the strategic maneuvering takes place can be of help in this endeavor. Fourth, we have to take into account what is the actual state of affairs in the discourse when the strategic maneuvering takes place, so that it can be explained to what situational demands exactly the strategic maneuvering must respond. An understanding of the mutual commitment sets defining the argumentative situation can be of help in this endeavor. If these four parameters are duly considered in analyzing the maneuvering manifesting itself in the discourse at the point the analyst is focusing on, it can be explained which strategic function a particular type of maneuvering, characterized by a certain combination of topical choice, audience orientation and presentational design, may fulfill.

These four parameters allow for taking account of a finite set of considerations that are pertinent to determining the type of strategic maneuvering that takes place in making a certain argumentative move at a specific point in the discourse. When taken together, they constitute a useful basis for analyzing the maneuvering in each of the four categories of strategic maneuvering. As a matter of course, the analysis starts from the way in which the strategic maneuvering manifests itself in the discourse, i.e., in a particular choice that is made from the available topical potential, a particular way in which the opportunities for framing the addressee's perspective are used, and a particular way in which the presentational possibilities are exploited. Although in strategic maneuvering these three aspects always go together, and are intrinsically connected, in argumentative practice one particular aspect is often more prominently manifested than the other aspects. The 
strategic maneuvering may, for instance, come primarily to the fore in the topical choice that is made, say by an emphatic use of an argument from authority (ex autoritate), or in the way audience adaptation is realized, say by emphatically adopting the other party's arguments (conciliatio), or in the use of presentational techniques, say by an emphatic repetition of the standpoint (repetitio). This is why it is, in our view, in principle recommendable to refer to the type of strategic maneuvering at issue by naming its most conspicuous manifestation in either of the three aspects: maneuvering by argument from authority, maneuvering by conciliation, maneuvering by repetition, etc. Subsequently, the four parameters we discussed can be used to analyze the specific strategic function a particular type of maneuvering at issue may have in the case where it is used.

\section{FALLACIES AS DERAILMENTS OF STRATEGIC MANEUVERING}

Although in strategic maneuvering the pursuit of dialectical objectives and the realization of rhetorical aims can go well together, this - of course - does not automatically mean that in practice there is always a perfect balance between pursuing the two objectives. If a party allows its commitment to a critical exchange of argumentative moves to be overruled by the aim of persuading the opponent, so that his moves are no longer in agreement with the critical norms, we say that the strategic maneuvering has got 'derailed.' Such derailments occur when a rule for critical discussion has been violated in the discourse. In that case, realizing the rhetorical aim has gained the upper hand at the expense of achieving the dialectical objective. Because derailments of strategic maneuvering always involve a violation of a rule for critical discussion, they are on a par with the wrong moves in argumentative discourse designated as fallacies. Viewed from this perspective, fallacies are violations of critical discussion rules that come about as derailments of strategic maneuvering.

This account of the fallacies as derailments of strategic maneuvering explains why in practice it may, as a matter of course, not be immediately apparent to all concerned that a fallacy has been committed, so that the fallacy can pass unnoticed: the fallacy will have sound counterparts that are manifestations of the same type of strategic maneuvering. Jackson (1995) has pointed out that it is an assumption of reasonableness that a party that maneuvers strategically will normally uphold a commitment to the rules of critical discussion, so that a presumption of reasonableness is conferred on every discussion move, also when a particular way of maneuvering is in fact fallacious. Echoing the logical Standard Definition of a fallacy, which was introduced 
and criticized by Hamblin (1970), we might say - in post-Hamblin pragma-dialectical terms - that fallacious strategic maneuvering seems to comply with the critical discussion rules, but does not. Deviations from the rules for critical discussion are often also hard to detect because none of the parties will be very keen on portraying themselves as being unreasonable. To realize a purpose that is potentially at odds with the observation of a particular discussion rule, rather than resorting to completely different means, they will therefore be inclined to stick to the dialectical means for achieving their objective that are considered reasonable and 'stretch' these means in such a way that they can still realize their purpose (cf. Kienpointner, 2006).

The difference between manifestations of strategic maneuvering that are legitimate and manifestations that are fallacious is that in the latter case certain soundness conditions have not been met that, at that point in the discourse, apply to the conduct of the type of strategic maneuvering concerned in the activity type and argumentative situation in which it occurs. In principle, each type of strategic maneuvering has, as it were, its own continuum of sound and fallacious acting and the boundaries between the two are not in all cases crystal clear. More often than not, fallacy judgments are in the end contextual judgments that depend on the specific circumstances of situated argumentative acting. The criteria for determining whether or not a certain norm for critical discussion has been violated may be dependent on the institutional conventions of the argumentative activity type concerned regarding how argumentative discourse is disciplined - in a law case, for instance, different criteria may apply to appealing to an authority than in a public debate, so that making an appeal to authority by referring to a certain law code may be a perfectly legitimate move in completing the argumentation stage whereas in a public debate making such an appeal may not be an appropriate move to conclude the argument. This predicament should, of course, not lead us to the general conclusion that there are no clear norms for determining when the strategic maneuvering has gone astray, but only to the conclusion that the way in which the criteria for deciding whether a norm has been complied with may vary to some extent from the one type of activity to the other, leaving room for the possibility that the criteria are in the one activity type more precisely articulated than in the other.

\section{STRATEGIC MANEUVERING WITH INCONSISTENCY}

As a case of disciplining argumentative conduct, we discuss the demarcation of non-fallacious and fallacious instances of a type of strategic maneuvering that takes place in the opening stage of a critical 
discussion in which the one party attacks the other party by pointing out a logical or pragmatic inconsistency between one of that party's starting points and a starting point that party assumed on a different occasion. Pointing out such an inconsistency can be a perfectly legitimate - and even very strong - strategic maneuver, but it can also derail and result in a tu quoque fallacy.

When considering inconsistencies between starting points we must distinguish between two kinds of starting points: (explicit or implicit) procedural starting points, and (explicit or implicit) material starting points. Ideally, both kinds of starting points should be fully clear, so that the parties involved in the discussion not only know how the discussion is going to be conducted but also what propositions they can safely bring to bear once the discussion has come off the ground. In order to conduct a proper critical discussion, the parties must agree in the opening stage about the division of the burden of proof, the discussion rules and the propositions that may be used in the argumentation stage to defend and challenge the standpoints at issue. In argumentative practice, in certain institutional contexts agreement about particular procedural and material starting points is presupposed. As far as procedural starting points are concerned, this goes, for instance, for activity (sub)types such as parliamentary debate; as far as material starting points are concerned, admissions made by the accused in the interrogation preceding the actual trial in a Dutch criminal law case provide a clear example: they can be used in court to establish conclusions weighing against or in favor of the accused, as the case may be.

In informal activity types there are usually no explicit agreements as to the material starting points. Generally, the parties use certain propositions as their starting points without asking for the other party's consent, but taking this consent, rightly or wrongly, for granted. All the same, there are a lot of cases in which it is first negotiated in a sub-discussion whether or not particular propositions may serve as a common starting point. Viewed dialectically, the parties are under no obligation to provide a reason for not admitting a proposition as a common starting point (van Eemeren and Grootendorst, 2004: Ch. 6). Viewed rhetorically, however, it may be better if they do: it is generally regarded of no use to start a discussion with people who refuse to commit themselves to any common starting point or, without giving any further explanation, to a specific starting point. Giving reasons for a refusal to admit a proposition as a common starting point can be a perfectly sound way of strategic maneuvering, but it can also derail into a fallacy, e.g., the fallacy of tu quoque. In the tu quoque case, the reason-giving amounts to saying that the protagonist's proposal to treat a proposition as a starting point is not acceptable because the proposition is inconsistent with something the protagonist has said or implied (by what he said or did) on a different occasion. 
When discussing the soundness conditions that make it possible to decide whether or not an antagonist maneuvers in an admissible way when refusing to admit a proposition as a starting point because of a proclaimed inconsistency between the proposed proposition and the protagonist's (verbal or non-verbal) behavior on a different occasion, we observe that these soundness conditions hinge on three points: (1) how is inconsistency to be defined so that it is possible to determine whether two propositions are logically or pragmatically inconsistent (a point of definition), (2) how can an accusation by the antagonist be incorporated that pertains to an inconsistency between the proposition presently proposed as a starting point and something that was earlier done (a matter of scope), and (3) what is in practice to be understood by 'on a different occasion,' so that it can be determined in a specific case whether pointing at an inconsistency makes sense from a dialectical perspective (a quasi-empirical issue).

\section{CONCLUSION}

By outlining a theoretical perspective on argumentative discourse that integrates rhetorical insight in a pragma-dialectical framework, we have developed an extended version of the pragma-dialectical theory of argumentation. This extended theory makes it possible to take the strategic design of the discourse into consideration in the analysis so that the reconstruction of argumentative discourse can be further refined and better accounted for. Because the strategic function of argumentative moves can now be taken into account, the extended theory also allows for a more accurate and realistic treatment of the fallacies in the evaluation of argumentative discourse that explains their potential persuasiveness as well as their treacherous character. In this way a new perspective for the study of argumentation is created that overcomes the traditional division between the dialectical approach and the rhetorical approach to argumentative discourse through enabling an integrated approach in which both dialectical and rhetorical insight are systematically taking into account.

\section{NOTES}

1 We realize that rhetoric is often defined in a more encompassing way, but the argumentative aspect our definition concentrates upon is always included and our definition leaves room for broader definitions.

${ }^{2}$ Note that we do not include rhetoric, as such, in dialectic but use insight from rhetoric in a dialectical analysis. Our procedure of embedding rhetorical insight in a dialectical analysis is not motivated ideologically but methodologically: our primary interest is the analysis of critical argumentative exchanges. 


\section{REFERENCES}

Eemeren, F. H. van and R. Grootendorst: 1984, Speech Acts in Argumentative Discussions: A Theoretical Model for the Analysis of Discussions Directed towards Solving Conflicts of Opinion, De Gruyter/Foris, Berlin/Dordrecht.

Eemeren, F. H. van and R. Grootendorst: 1992, Argumentation, Communication, and Fallacies: A Pragma-Dialectical Perspective, Lawrence Erlbaum Associates, Hillsdale, NJ.

Eemeren, F. H. van and R. Grootendorst: 2004, A Systematic Theory of Argumentation. The Pragma-Dialectical Approach, Cambridge University Press, Cambridge.

Eemeren, F. H. van, R. Grootendorst, S. Jackson and S. Jacobs: 1993, Reconstructing Argumentative Discourse, The University of Alabama Press, Tuscaloosa and London.

Eemeren, F. H. van, R. Grootendorst, A. F. Snoeck Henkemans, J. A. Blair, R. H. Johnson, E. C. W. Krabbe, Chr. Plantin, D. N. Walton, C. A. Willard, J. Woods and D. Zarefsky: 1996, Fundamentals of Argumentation Theory: A Handbook of Historical Backgrounds and Contemporary Developments, Lawrence Erlbaum, Mahwah, NJ.

Eemeren, F. H. van and P. Houtlosser: 2002, 'Strategic maneuvering: Maintaining a delicate balance', in F. H. van Eemeren and P. Houtlosser (eds), Dialectic and Rhetoric: The Warp and Woof of Argumentation Analysis, Kluwer Academic Publishers, Dordrecht.

Hamblin, C. L.: 1970, Fallacies, Reprinted at Newport News: Vale Press, Methuen, London.

Jackson, S.: 1995, 'Fallacies and heuristics', in F. H. van Eemeren, R. Grootendorst, J. A. Blair and C. A. Willard (eds), Analysis and Evaluation. Proceedings of the Third ISSA Conference on Argumentation, vol. II, pp. 257-269, Sic Sat, Amsterdam.

Kauffeld, F.: 2002, 'Pivotal issues and norms in rhetorical theories of argumentation', in F. H. van Eemeren and P. Houtlosser (eds), Dialectic and Rhetoric: The Warp and Woof of Argumentation Analysis, pp. 97-118, Kluwer Academic, Dordrecht etc.

Kienpointner, M.: 2006, 'How to present fallacious messages persuasively: The case of the "Nigeria Spam Letters", in P. Houtlosser and M. A. van Rees (eds), Considering Pragma-Dialectics, pp. 161-173, Lawrence Erlbaum Associates, Mahwah, N.J./London.

Krabbe, E. C. W.: 2002, 'Meeting in the house of Callias: An historical perspective on rhetoric and dialectic', in F. H. van Eemeren and P. Houtlosser (eds), Dialectic and Rhetoric: The Warp and Woof of Argumentation Analysis, pp. 29-40, Kluwer Academic, Dordrecht etc.

Leeman, A. D.: 1992, 'Rhetoric versus Argumentation Theory', in F. H. van Eemeren, R. Grootendorst, J. A. Blair and C. A. Willard (eds), Argumentation Illuminated, pp. 12-22, Sic Sat, Amsterdam.

Leff, M.: 2002, The relation between rhetoric and dialectic in a classical and a modern perspective. in F. H. van Eemeren and P. Houtlosser (eds.), Dialectic and Rhetoric: The Warp and Woof of Argumentation Analysis, pp. 53-63, Kluwer Academic, Dordrecht etc.

Leff, M.: 2006, 'Rhetoric, dialectic, and the functions of argument', in P. Houtlosser and M. A. van Rees (eds), Considering Pragma-Dialectics, pp. 199-209, Lawrence Erlbaum Associates, Mahwah, N.J./London.

Tindale, Ch. W.: 2004, Rhetorical Argumentation: Principles of Theory and Practice, Sage, Thousand Oaks etc.

Toulmin, S. E.: 2001, Return to Reason, Harvard University Press, Cambridge, Mass.

Walton, D. N. and E. C. W. Krabbe: 1995, Commitment in Dialogue: Basic Concepts of Interpersonal Reasoning, State University of New York Press, Albany, NY.

Wenzel, J. W.: 1990, Three Perspectives on Argument: Rhetoric, Dialectic, Logic, in R. Trapp and J. Schuetz (eds.), Perspectives on Argumentation: Essays in the Honor of Wayne Brockriede, pp. 9-26, Waveland: Prospect Heights, Ill. 
Zarefsky, D.: 2006, 'The ten rules of pragma-dialectics and validity in argumentation', in P. Houtlosser and M. A. van Rees (eds), Considering Pragma-Dialectics, pp. 313-323, Lawrence Erlbaum Associates, Mahwah, N.J./London. 